Supporting Information

\title{
Toward Efficient Triple-Junction Polymer Solar Cells through Rational Selection of Middle Cells
}

Fang-Xiao Chen, ${ }^{\dagger}$ Ran Qin, ${ }^{\dagger}$ Ruoxi Xia, ${ }^{\dagger}$ Yingzhu Zhang, ${ }^{\dagger}$ Lijian Zuo ${ }^{\S}$ Hin-Lap Yip, *Hongzheng Chen ${ }^{\dagger}$ and Chang-Zhi Li†,*

'State Key Laboratory of Silicon Materials, MOE Key Laboratory of Macromolecular Synthesis and Functionalization, Department of Polymer Science and Engineering, Zhejiang University, Hangzhou 310027, P. R. China

*State Key Laboratory of Luminescent Materials and Devices, School of Materials Science and Engineering, South China University of Technology, 381 Wushan Road, Guangzhou 510640, P. R. China

$\S$ Department of Materials Science and Engineering, University of Washington, Seattle, WA 98195, USA

*email: czli@zju.edu.cn 


\section{Experimental Section}

\section{Materials}

Unless stated otherwise, solvents and materials were purchased from J\&K Scientific, Suna Tech, MiliporeSigma and Energy Chemical Ltd. and were used without further purification.

\section{General characterization}

UV-vis absorption spectra were recorded on a Shimadzu UV-2450 spectrophotometer. Cyclic voltammetry (CV) was done on a CHI600A electrochemical workstation with Pt disk, Pt plate, and standard calomel electrode (SCE) as working electrode, counter electrode, and reference electrode, respectively, in a $0.1 \mathrm{~mol} / \mathrm{L}$ tetrabutylammoniumhexafluorophosphate $\left(\mathrm{Bu}_{4} \mathrm{NPF}_{6}\right) \mathrm{CH}_{2} \mathrm{Cl}_{2}$ solution. The equation $\mathrm{E}_{\mathrm{LUMO} / \mathrm{HOMO}}=-\mathrm{e}\left(\mathrm{E}_{\mathrm{red} / \mathrm{ox}}+4.36\right)(\mathrm{eV})$ is used to calculate the lowest unoccupied molecular orbital (LUMO) and highest occupied molecular orbital (HOMO) levels because in our lab the redox potential of $\mathrm{Fc} / \mathrm{Fc}^{+}$is measured as $0.44 \mathrm{~V}$ (the energy level of $\mathrm{Fc} / \mathrm{Fc}^{+}$as $4.80 \mathrm{eV}$ below vacuum).

\section{Instruments and measurements}

The current density-voltage (J-V) curves of PSCs were measured with Keithley 2400, under AM 1.5G illumination at $100 \mathrm{~mW} \mathrm{~cm}^{-2}$ irradiation using a Enli SS-F5-3A solar simulator, and the light intensity was calibrated with a standard Si solar cell (made by Enli Technology Co., Ltd., Taiwan, and calibrated report can be traced to NREL). The EQE spectrum was measured using a QE-R Solar Cell Spectral Response Measurement System (Enli Technology Co., Ltd., Taiwan).

Device Fabrication and Characterization: Polymer solar cells were fabricated on glass substrates commercially pre-coated with a layer of indium tin oxide (ITO) with the inverted structure of ITO/ZnO/BHJ $/ \mathrm{MoO}_{3} / \mathrm{Ag}$ for SJ-PSCs, and with the structure of ITO/ZnO/PBDD-T-2F: $\mathrm{PC}_{71} \mathrm{BM} / \mathrm{MoO}_{3} / \mathrm{Ag} / \mathrm{ZnO}-\mathrm{NP} / \mathrm{PFN}-\mathrm{Br} / \mathrm{PBDB}-\mathrm{T}$ : ITIC (or PBDB-T: HF-TCIC)/ $\mathrm{MoO}_{3} / \mathrm{Ag} / \mathrm{ZnO}-\mathrm{NP} / \mathrm{PFN}-\mathrm{Br} / \mathrm{PTB} 7-\mathrm{Th}: \mathrm{IEICO}-4 \mathrm{~F} / \mathrm{MoO}_{3} / \mathrm{Ag}$ for TJ-PSCs. Before fabrication, the substrates were cleaned using detergent, deionized water, acetone, isopropanol and ethanol consecutively for every 15 mins, and then treated in an ultraviolet ozone generator for $5 \mathrm{~min}$. The sol-gel $\mathrm{ZnO}$ was fabricated from Zinc acetate dihydrate solution in 2-methoxyethanol and 2-aminoethanol. The $\mathrm{ZnO}$ nanoparticles were synthesis through a hydrolysis process with Zinc acetate dihydrate as precursor. In more details, a stoichiometric amount of tetramethylammonium hydroxide (TMAH) dissolved in ethanol $(0.55 \mathrm{M}, 5.45 \mathrm{ml})$ was added dropwise to $\mathrm{Zn}$ acetate dehydrated $(0.1 \mathrm{M}, 30 \mathrm{ml})$ dissolved in DMSO followed by stirring for an hour at room temperature. After rinsing twice, the $\mathrm{ZnO}$ particles were dispersed in ethanol solution with a concentration of $\sim 10 \mathrm{mg} / \mathrm{ml}$.

Single junction cell: A thin layer of sol-gel $\mathrm{ZnO}$ was fabricated by spin coating of Zinc dihydrate acetate solution onto precleaned ITO-coated glass substrates at 3500 
rpm for $60 \mathrm{~s}$ and then annealed at $170{ }^{\circ} \mathrm{C}$ for $20 \mathrm{~min}$. Then the substrates were transferred into a glovebox; the active layer was spin coated from $20 \mathrm{mg} / \mathrm{mL}$ chlorobenzene solution of PBDB-T-2F: $\mathrm{PC}_{71} \mathrm{BM}(1: 1.5 \mathrm{wt} \%)$ with $3 \%$ DIO additive at $2500 \mathrm{rpm}$ for $60 \mathrm{~s}$. The PBDB-T: ITIC blends were spin-coated from a $20 \mathrm{mg} / \mathrm{mL}$ PBDB-T: ITIC (1:1.5 wt\%) solution in the mixed solvent of CB and DIO (99.5:0.5 vol.\%) at $2500 \mathrm{rpm}$ for $60 \mathrm{~s}$, followed by thermal annealing at $100{ }^{\circ} \mathrm{C}$ for $10 \mathrm{~min}$. The PBDB-T: HF-TCIC blends were spin-coated from a $18 \mathrm{mg} / \mathrm{mL}$ PBDB-T: ITIC (1:1.2 $w t \%)$ solution in the mixed solvent of $\mathrm{CF}$ and $\mathrm{CN}(99.5: 0.5 \mathrm{vol} . \%)$ at $3500 \mathrm{rpm}$ for $45 \mathrm{~s}$, followed by thermal annealing at $120{ }^{\circ} \mathrm{C}$ for $10 \mathrm{~min}$. The PTB7-Th: IEICO-4F blends were spun from a $25 \mathrm{mg} / \mathrm{mL}$ PTB7-Th: IEICO-4F $(1: 1.5 \mathrm{wt} \%)$ solution in the mixed solvent of $\mathrm{CB}$ and $\mathrm{CN}(97: 3 \mathrm{vol} . \%)$ at $3500 \mathrm{rpm}$ for $60 \mathrm{~s}$. Finally, a layer of $\mathrm{MoO}_{3}(4 \mathrm{~nm})$ and the $\mathrm{Ag}(100 \mathrm{~nm})$ electrode were deposited by thermal evaporation to complete the device with an active area of $6 \mathrm{~mm}^{2}$.

Triple junction cell: the active layers for the front cells were first spin-coated atop of $\mathrm{ZnO} / \mathrm{ITO}$ substrates from $20 \mathrm{mg} / \mathrm{mL}$ chlorobenzene solution of PBDB-T-2F: $\mathrm{PC}_{71} \mathrm{BM}$ (1:1.5 wt $\%)$ with $3 \%$ DIO additive. Then, $\mathrm{MoO}_{3}(6 \mathrm{~nm})$ and ultrathin $\mathrm{Ag}(0.6 \mathrm{~nm})$ were deposited via thermal evaporation. The deposition of the ultrathin Ag layer was defined by a mask with good alignment to the patterned ITO strip. Atop of ultrathin $\mathrm{Ag}$ layer, $\mathrm{ZnO}-\mathrm{NP}$ and $\mathrm{PFN}-\mathrm{Br}$ in methanol were subsequently spin-coated to complete ICL fabrication (Note that the ICL layer was later divided into separated pieces with a scalpel according to the top silver electrodes). Afterwards, the active layer for the middle cell was spin-coated from $20 \mathrm{mg} / \mathrm{ml}$ chlorobenzene solution of PBDB-T: ITIC (1:1 wt \%), and $18 \mathrm{mg} / \mathrm{ml}$ chloroform solution of PBDB-T: HF-TCIC $(1: 1.2 \mathrm{wt} \%)$, respectively. Then, $\mathrm{MoO}_{3}(6 \mathrm{~nm})$ and ultrathin $\mathrm{Ag}(0.6 \mathrm{~nm})$ were deposited via thermal evaporation. The deposition of the ultrathin Ag layer was defined by a mask with good alignment to the patterned ITO strip. Atop of ultrathin $\mathrm{Ag}$ layer, $\mathrm{ZnO}-\mathrm{NP}$ and $\mathrm{PFN}-\mathrm{Br}$ in methanol were subsequently spin-coated to complete ICL fabrication. Afterwards, the rear cell was spin-coated from $25 \mathrm{mg} / \mathrm{ml}$ solution of PTB7-Th: IEICO-4F $(1: 1.5 \mathrm{wt} \%)$ with a mixed solvent of CB and CN (97:3 vol.\%). The triple junction device was completed by evaporating $4 \mathrm{~nm} \mathrm{MoO}_{3}$ and $100 \mathrm{~nm} \mathrm{Ag}$ to complete the device with an active area of $6 \mathrm{~mm}^{2}$.

\section{Optical simulations}

The algorithm of the optical model is based on the Transfer Matrix Formalism Model (TMM). This theory assumes that all layers are homogeneous and their interfaces are flat and parallel so that each layer can be described by its thickness and optical constant. Complex refractive index $(\mathrm{N}=\mathrm{n}+\mathrm{k} * \mathrm{i})$, which consists of the refractive index ( $n$ value) and extinction coefficient ( $k$ value) and all of these parameters can be determined by spectroscopic ellipsometry (ME-L ellipsometer, Wuhan Eoptics Technology). The probed wavelength range of Psi and Delta is $350-1650 \mathrm{~nm}$. In general, we first use Cauchy model to fit the transparent region of organic semiconductor. Then, Bspline is used for the remaining part. After that, the parameterization is performed with combinations of Tauc-Lorentz model and 
Gaussian model. Finally, film thickness, incidence angle, roughness, and all model parameters are optimized simultaneously for a small enough mean square error (MSE).

\section{Energy loss analysis in polymer solar cells}

In PSCs, the conversion of photons to electrons process occurs in distinct steps, which includes light absorption or exciton generation, exciton separation or free carrier generation, and charge extraction, each with its own induced energy loss. For example, during the light absorption, photons with energy lower than the band-gap are not harvested, causing the Transmission Loss, which can be calculated as:

$E_{\text {tran }}=\int_{0}^{E_{g}} \Phi(h v) d h v$

where $\Phi(h v)$ is solar energy spectrum. Eg is the band-gap of solar cell system, and hv is the photon energy. Even within the absorbing wavelength region of active layers, not all photons can be absorbed by the OSCs due to specific device geometry and thin active layers, and the loss of unabsorbed photons within the absorbing region is termed as Insufficient Light Absorbing Loss:

$E_{a b s}=\int_{E_{g}}^{4.43 e V}(1-E Q E 100 \% I Q E, h v) \Phi(h v) d h v$

where the EQE (100\% IQE, hv) is the EQE of device assuming the device IQE is $100 \%$, which can be estimated from the optical simulation and reflectance spectra.

After light absorption, the electrons are excited to higher energy levels, but will quickly relax to the lowest unoccupied molecular orbital (LUMO) of the molecules via thermalization. The excessive energy of photons over the band gap of active layer materials is termed as Thermalization Energy Loss:

$E_{\text {therm }}=\int_{E_{g}}^{4.33 \mathrm{eV}}(1-E g / h v) E Q E h v \Phi(h v) d h v$

With the electrons relaxed to the LUMO levels, exciton separation and charge transport and extraction occur via complicated carrier dynamics, which involve formation of CT states and charge recombination in the bulk heterojunction and electrode interfaces. The energy loss during the carrier dynamic process is termed as Carried Dynamic Loss, which can be classified into three species. First, although the electrons relax to the LUMO of the active layer materials, the output VOC is smaller than the band-gap of the active layers. The energy loss between the Eg and VOC (or VOC deficit) is termed as VOC loss:

$$
\left.E_{V_{o c}}=\int_{E_{g}}^{4.33 e V}[(E g-V O C) / h v] E Q E h v\right) \Phi(h v) d h v
$$

Second, during the carrier dynamic process, electrons can also be annihilated via charge recombination, leading to the non-unity of IQE in OSCs. The energy loss from the non-unity IQE is termed as IQE loss: 
$E_{I Q E}=\int_{E_{g}}^{4.33 \mathrm{eV}}(1-I Q E h v E Q E 100 \% I Q E, h v) \Phi h v d h v$

Third, the charge recombination shows severe bias dependent behavior, indicating that the energy loss can be induced during the real working condition. The energy loss between the theoretical output power (JSC*VOC) and the feasible maximum output power can be expressed by the non-unity FF, and thus, this energy loss is termed as FF loss:

$$
E_{F F}=(1-F F)\left(\int_{E_{g}}^{4.33 e V} \Phi h v d h v-E_{t r a n s}-E_{a b s}-E_{t h e r m}-E_{V_{o c}}-\mathrm{E}_{\mathrm{IQE}}\right)
$$

Since the measured EQE can present the energy loss from insufficient light absorption and IQE during carrier dynamic, we combine these two energy loss channels by integrating EQE over the light absorption range of device, and these energy losses can be calculated as:

$$
E_{a b s}+E_{I Q E}=\int_{E_{g}}^{4.33 e V}(1-E Q E h v) \Phi(h v) d h v
$$
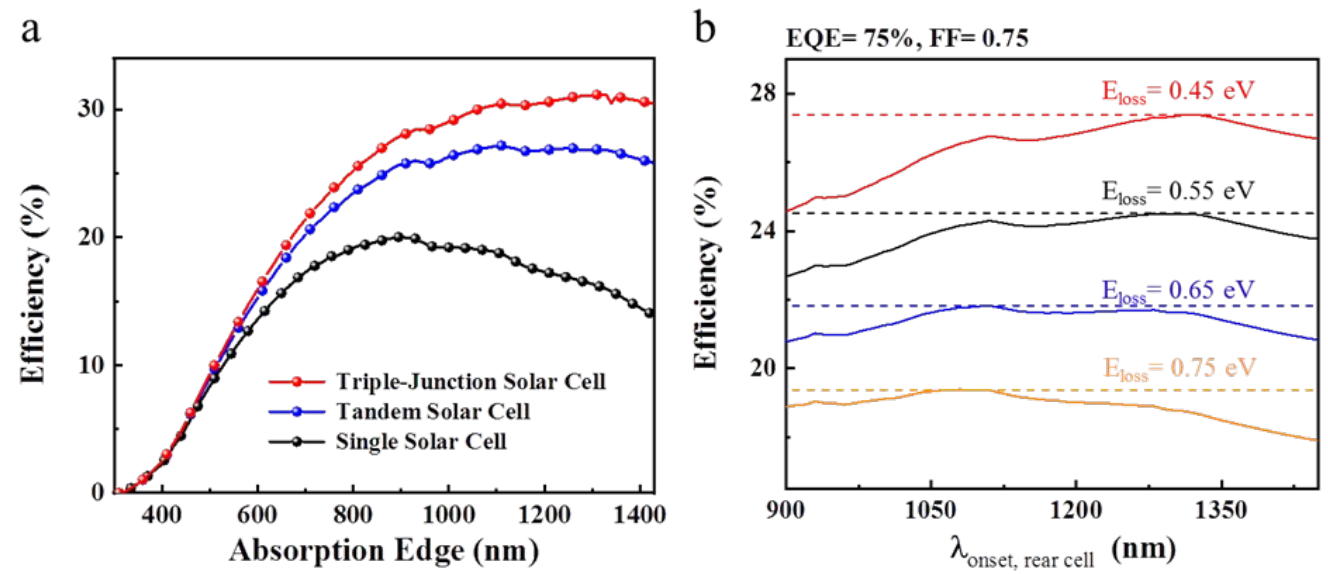

Figure S1. Semiempirical model analysis of multi-junction cell efficiency under AM $1.5 \mathrm{G}$ a) The effect of the number of sub-cells and absorption edge on multi-junction cell efficiency (assumed FF $=0.80$, and $\mathrm{EQE}=80 \%$ ). $\mathrm{b}$ ) The effect of $\lambda$ onset, rear cell (absorption edge of rear cell) and voltage loss $\left(\mathrm{E}_{\mathrm{loss}}\right)$ on triple-junction cell efficiency (assumed $\mathrm{FF}=0.75$, and $\mathrm{EQE}=75 \%$ ). The analysis was performed under following assumptions: (1) subcells were connected in series with no contact loss; (2) each subcell produce same current density with no current loss. The simulation method we adapted herein can be traced back to literature (Energy Environ. Sci., 2010, 3, 867883, Energy Environ. Sci., 2013, 6, 3150-3170), whereas with fairly updating the FF, EQE and $\mathrm{E}_{\mathrm{loss}}$ of PSCs to current status. 


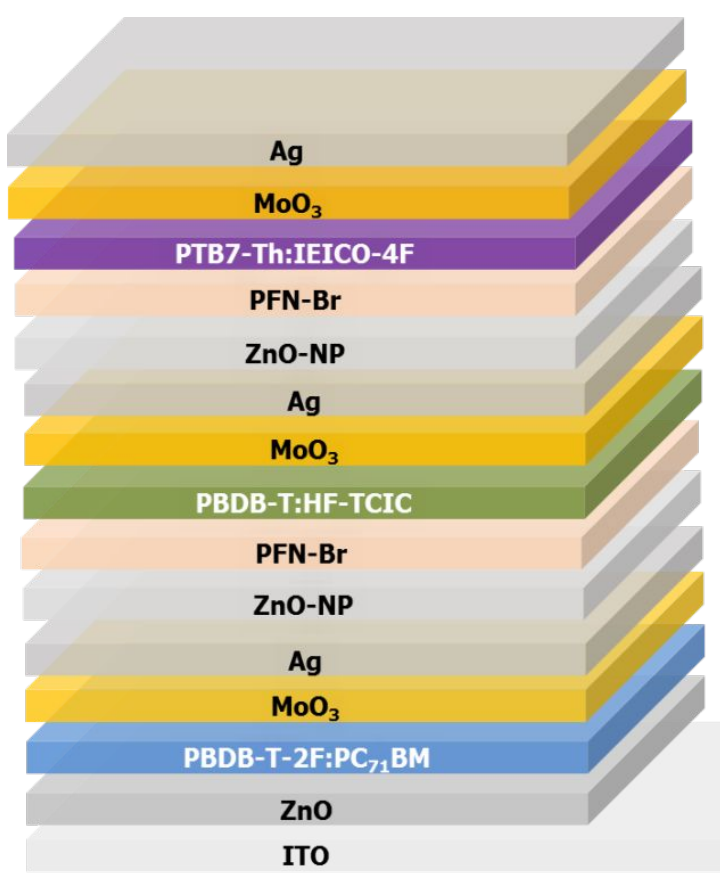

Figure S2. The detailed schematic architecture of triple-junction polymer solar cell.
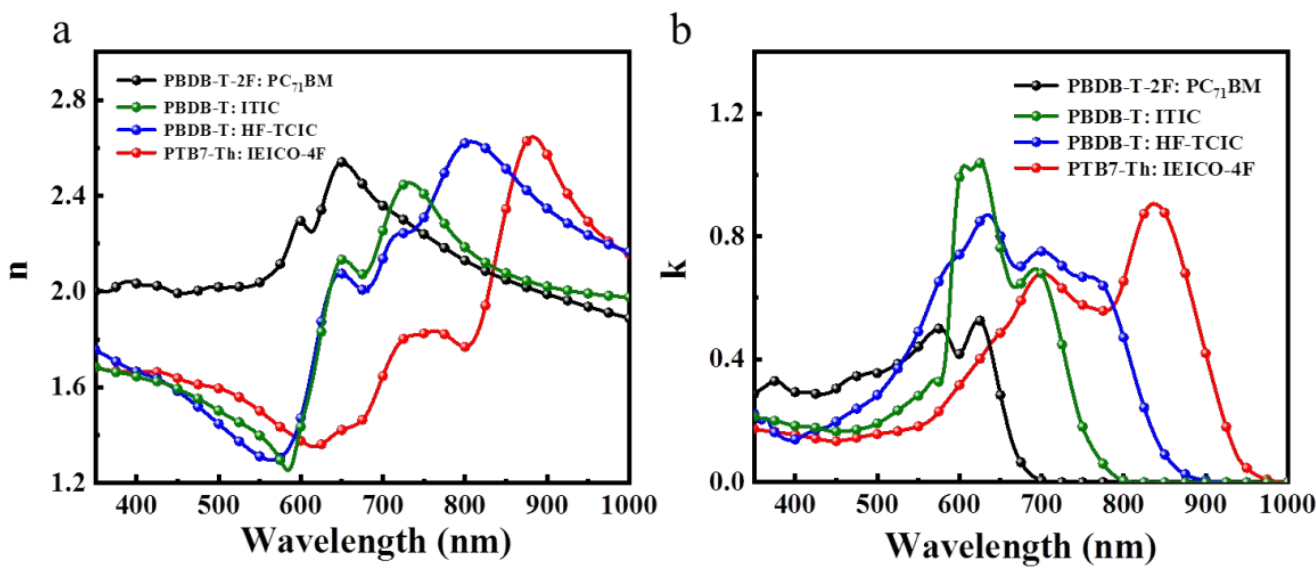

Figure S3. (a) Optical parameters $\mathrm{n}$ of PBDB-T-2F: $\mathrm{PC}_{71} \mathrm{BM}$, PBDB-T: ITIC, PBDB-T: HF-TCIC and PTB7-Th: IEICO-4F. (b) Optical parameters $k$ of PBDB-T-2F: PC ${ }_{71}$ BM, PBDB-T: ITIC, PBDB-T: HF-TCIC and PTB7-Th: IEICO-4F. 


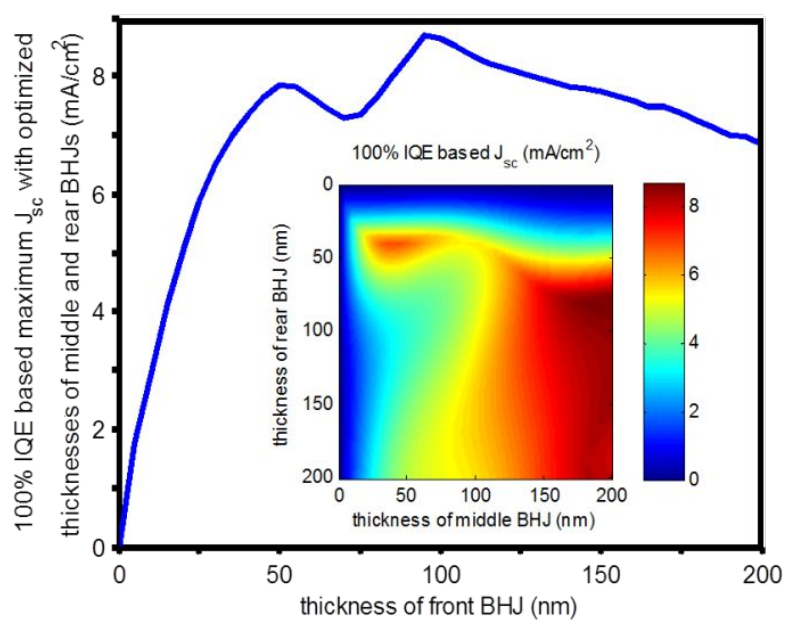

Figure S4. Simulated $J_{S C}$ generated in triple-junction solar cells as a function of the thickness of the front (PBDB-T-2F: PC $_{71} \mathrm{BM}$ ), middle (PBDB-T: ITIC) and rear (PTB7-Th: IEICO-4F) cells.

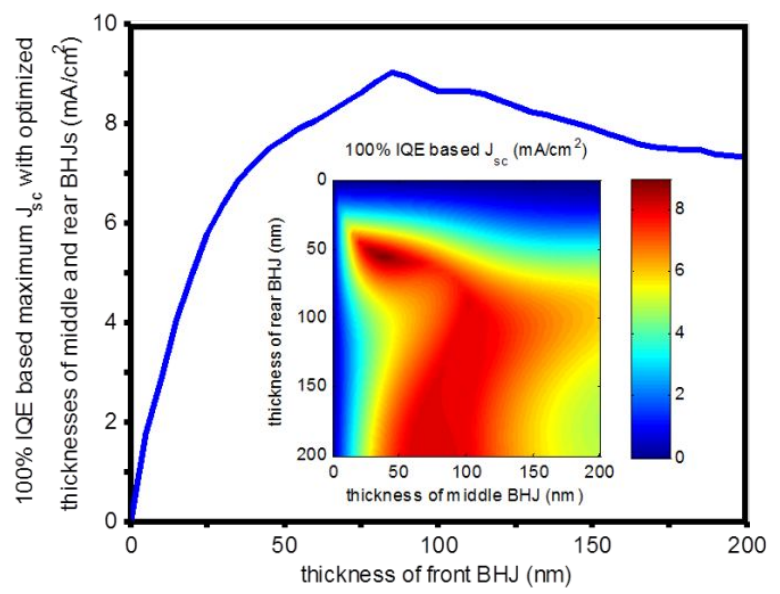

Figure S5. Simulated $J_{S C}$ generated in triple-junction solar cells as a function of the thickness of the front (PBDB-T-2F: PC ${ }_{71} \mathrm{BM}$ ), middle (PBDB-T: HF-TCIC) and rear (PTB7-Th: IEICO-4F) cells. 


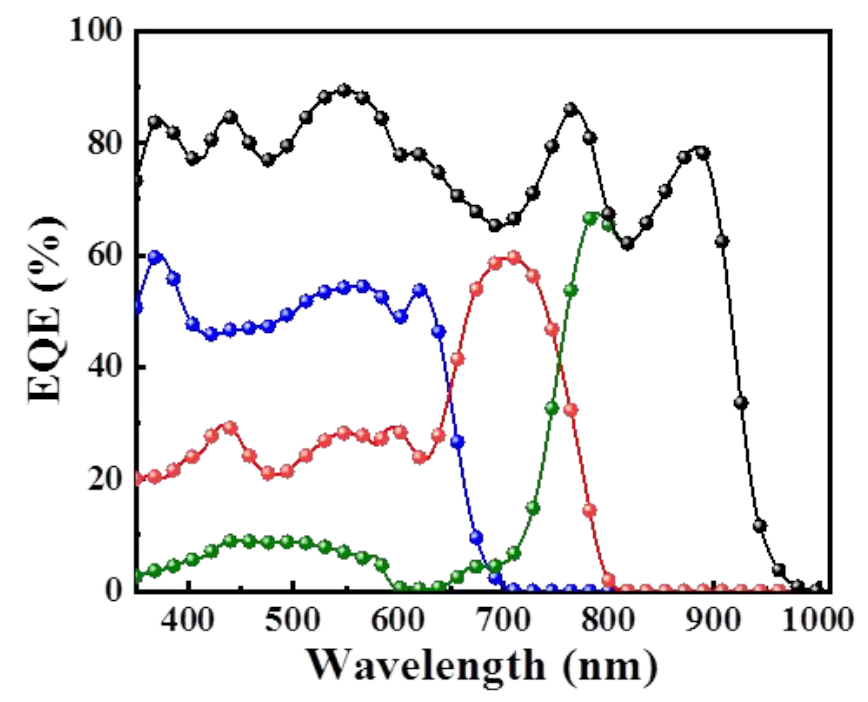

Figure S6. Simulated EQE for the best TJ-PSCs (Blue curve, PBDB-T-2F: $\mathrm{PC}_{71} \mathrm{BM}$ front cell; Red curve, PBDB-T: ITIC middle cell; Green curve, PTB7-Th: IEICO-4F rear cell; And black curve, the summed $\mathrm{EQE}$ from three sub-cells) under experimental layer thicknesses.

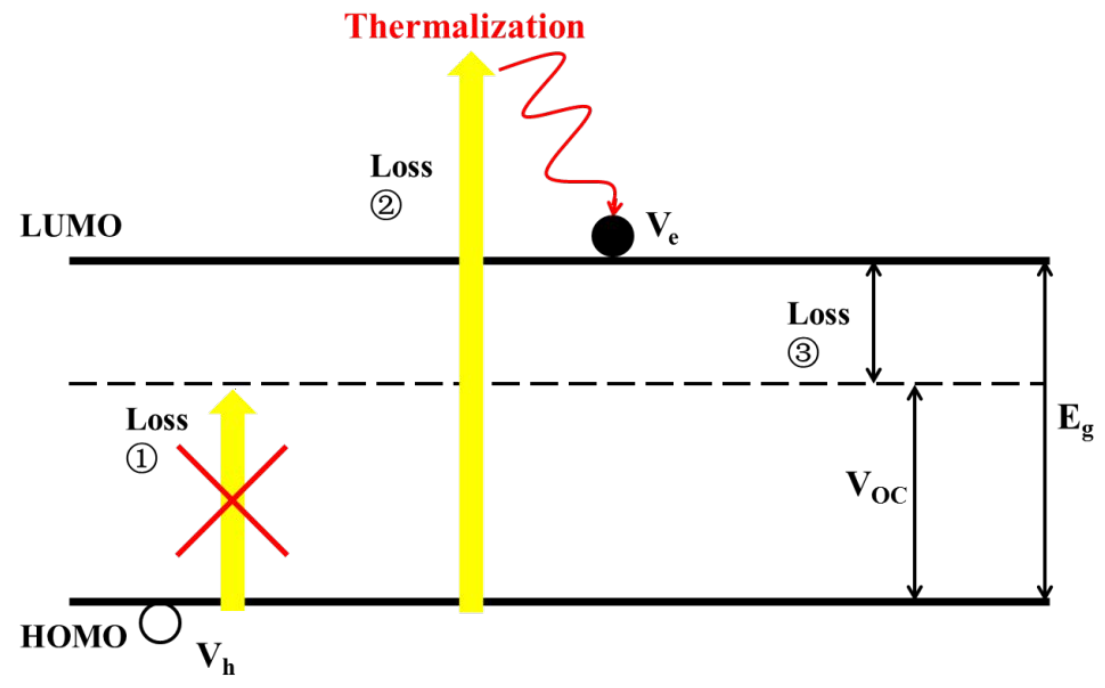

(1) Transmission loss (2) Thermalization loss (3) Voc loss

Figure S7. Energy schematic of transmission loss, thermalization loss and Voc loss. 
Table S1. High-efficiency TJ-PSCs reported in recent years.

\begin{tabular}{|c|c|c|c|c|c|c|c|}
\hline Front Cell & Middle Cell & Rear Cell & $\begin{array}{l}\text { Jsc } \\
\left(\mathrm{mA} \mathrm{cm}{ }^{-2}\right)\end{array}$ & $\begin{array}{l}\text { Voc } \\
\text { (V) }\end{array}$ & FF & $\begin{array}{l}\text { PCE } \\
(\%)\end{array}$ & Ref. \\
\hline PDBT-T1:TPH-Se:ITIC & PBDB-T:ITIC & PTB7-Th:IEICO-4F & 8.20 & 2.52 & 0.64 & 13.00 & 1 \\
\hline PSEHTT:IC ${ }_{60} \mathrm{BA}$ & PTB7:PC ${ }_{70} \mathrm{BM}$ & PMDPP3T:PC ${ }_{71} \mathrm{BM}$ & 7.83 & 2.24 & 0.68 & 11.83 & 2 \\
\hline P3HT:ICBA & PTB:PC ${ }_{71} \mathrm{BM}$ & LBG:PC ${ }_{71} \mathrm{BM}$ & 7.63 & 2.28 & 0.66 & 11.55 & 3 \\
\hline $\mathrm{DBP}: \mathrm{C}_{70}$ & DTDCTB: $\mathrm{C}_{60}$ & $\mathrm{DBP}: \mathrm{C}_{70}$ & 7.30 & 2.58 & 0.59 & 11.10 & 4 \\
\hline PDCBT:PC ${ }_{60} \mathrm{BM}$ & PTB7-Th:PC ${ }_{70} \mathrm{BM}$ & PMDPP3T:PC 60 BM & 7.42 & 2.20 & 0.66 & 10.77 & 5 \\
\hline Ph2-benz-bodipy: $\mathrm{C}_{60}$ & DCV5T-Me: $\mathrm{C}_{60}$ & DCV5T-Me:C60 & 6.50 & 2.63 & 0.61 & 10.40 & 6 \\
\hline PCDTBT:PC ${ }_{70} \mathrm{BM}$ & PMDPP3T:PC 60 BM & PMDPP3T:PC ${ }_{60} \mathrm{BM}$ & 7.34 & 2.09 & 0.63 & 9.64 & 7 \\
\hline PBDB-T-2F:PC ${ }_{71} \mathrm{BM}$ & PBDB-T:ITIC & PTB7-Th:IEICO-4F & 6.82 & 2.46 & 0.68 & 11.41 & This work \\
\hline PBDB-T-2F:PC ${ }_{71} \mathrm{BM}$ & PBDB-T:HF-TCIC & PTB7-Th:IEICO-4F & 8.50 & 2.37 & 0.65 & 13.09 & This work \\
\hline
\end{tabular}

Table S2. TJ-PSCs device performance with varied thicknesses of PBDB-T: ITIC middle cell (PBDB-T-2F: PC ${ }_{71} \mathrm{BM}$ front cell and PTB7-Th: IEICO-4F rear cell).

\begin{tabular}{lllllll}
\hline $\begin{array}{l}\text { Front } \\
{[\mathrm{nm}]}\end{array}$ & $\begin{array}{l}\text { Middle } \\
{[\mathrm{nm}]}\end{array}$ & $\begin{array}{l}\text { Rear } \\
{[\mathrm{nm}]}\end{array}$ & $\begin{array}{l}\mathrm{V}_{\mathrm{OC}} \\
{[\mathrm{V}]}\end{array}$ & $\begin{array}{l}\mathrm{J}_{\mathrm{SC}} \\
{\left[\mathrm{mA} \mathrm{cm}{ }^{-2}\right]}\end{array}$ & FF & $\begin{array}{l}\text { PCE } \\
{[\%]}\end{array}$ \\
\hline 95 & 100 & 120 & 2.46 & 6.10 & 0.66 & 9.90 \\
95 & 110 & 120 & 2.46 & 6.50 & 0.68 & 10.87 \\
95 & 120 & 120 & 2.46 & 6.82 & 0.68 & 11.41 \\
95 & 130 & 120 & 2.46 & 6.61 & 0.68 & 11.06 \\
95 & 140 & 120 & 2.46 & 6.21 & 0.67 & 10.24 \\
95 & 150 & 120 & 2.45 & 6.01 & 0.67 & 9.87 \\
\hline
\end{tabular}


Table S3. TJ-PSCs device performance with varied thicknesses of PBDB-T : HF-TCIC middle cell (PBDB-T-2F: PC ${ }_{71}$ BM front cell and PTB7-Th: IEICO-4F rear cell).

\begin{tabular}{lllllll}
\hline $\begin{array}{l}\text { Front } \\
{[\mathrm{nm}]}\end{array}$ & $\begin{array}{l}\text { Middle } \\
{[\mathrm{nm}]}\end{array}$ & $\begin{array}{l}\text { Rear } \\
{[\mathrm{nm}]}\end{array}$ & $\begin{array}{l}\mathrm{V}_{\mathrm{OC}} \\
{[\mathrm{V}]}\end{array}$ & $\begin{array}{l}\mathrm{J}_{\mathrm{SC}} \\
{\left[\mathrm{mA} \mathrm{cm}{ }^{-2}\right]}\end{array}$ & FF & $\begin{array}{l}\text { PCE } \\
{[\%]}\end{array}$ \\
\hline 85 & 40 & 55 & 2.33 & 7.65 & 0.60 & 10.69 \\
75 & 100 & 90 & 2.37 & 8.29 & 0.64 & 12.57 \\
85 & 90 & 90 & 2.36 & 8.14 & 0.65 & 12.49 \\
85 & 100 & 80 & 2.37 & 8.35 & 0.64 & 12.67 \\
85 & 100 & 90 & 2.37 & 8.50 & 0.65 & 13.09 \\
95 & 100 & 90 & 2.36 & 8.24 & 0.64 & 12.45 \\
85 & 110 & 90 & 2.37 & 8.19 & 0.65 & 12.62 \\
85 & 100 & 100 & 2.37 & 8.10 & 0.65 & 12.48 \\
\hline
\end{tabular}

\section{References}

(1) Huang, W.; Chang, S. Y.; Cheng, P.; Meng, D.; Zhu, B.; Nuryyeva, S.; Zhu, C.; Huo, L.; Wang, Z.; Wang, M.; Yang, Y., High Efficiency Non-fullerene Organic Tandem Photovoltaics Based on Ternary Blend Subcells. Nano. Lett. 2018, 18, 7977-7984.

(2) Adebanjo, O.; Maharjan, P. P.; Adhikary, P.; Wang, M. T.; Yang, S. F.; Qiao, Q. Q., Triple junction polymer solar cells. Energy Environ. Sci.

2013, 6, 3150-3170.

(3) Chen, C. C.; Chang, W. H.; Yoshimura, K.; Ohya, K.; You, J.; Gao, J.; Hong, Z.; Yang, Y., An efficient triple-junction polymer solar cell having a power conversion efficiency exceeding 11\%. Adv. Mater. 2014, 26, 5670-5677.

(4) Che, X. Z.; Xiao, X.; Zimmerman, J. D.; Fan, D. J.; Forrest, S. R., High-Efficiency, Vacuum-Deposited, Small-Molecule Organic Tandem and Triple-Junction Photovoltaic Cells. Adv. Energy Mater. 2014, 4, 1400568.

(5) Rasi, D. D.; Hendriks, K. H.; Wienk, M. M.; Janssen, R. A. J., Accurate Characterization of Triple-Junction Polymer Solar Cells. Adv. Energy Mater. 2017, 7, 1701664.

(6) Meerheim, R.; Korner, C.; Oesen, B.; Leo, K., 10.4\% Efficient triple organic solar cells containing near infrared absorbers. Appl. Phys. Lett. 2016, 108.

(7) Li, W. W.; Furlan, A.; Hendriks, K. H.; Wienk, M. M.; Janssen, R. A. J., Efficient Tandem and Triple-Junction Polymer Solar Cells. J. Am. Chem. Soc 2013, 135, 5529-5532. 